\title{
Preface to JAISE 14(1)
}

\author{
Andrés Muñoz ${ }^{\mathrm{a}}$, Juan Carlos Augusto ${ }^{\mathrm{b}}$, Vincent Tam ${ }^{\mathrm{c}}$ and Hamid Aghajan ${ }^{\mathrm{d}}$ \\ ${ }^{a}$ Department of Computer Science, University of Cadiz, Spain \\ ${ }^{\mathrm{b}}$ Department of Computer Science and Research Group on Development of Intelligent Environments, Middlesex \\ University, $U K$ \\ ${ }^{\mathrm{c}}$ Department of Electrical and Electronic Engineering, Faculty of Engineering, The University of Hong Kong, \\ China \\ d imec, IPI, Department of Telecommunications and Information Processing, Gent University, Belgium
}

\section{This thematic issue}

Thanks to rapid advances in computing and artificial intelligence, the goal of developing intelligent systems for effective and universal healthcare is not just a far-reaching objective anymore. Still, the computer science and ambient intelligence communities are facing several challenges that need to be addressed in the next several years, such as the management of the vast amount of data generated by modern healthcare systems, which exceeds that of any other industry; the representation, sharing and use of the acquired knowledge in and between the healthcare computing networks; and managing the interplay between user privacy and safety and the healthcare system's effectiveness, among others. In this context, researchers in the area of ambient intelligence will play a critical role in responding to all these challenges, thanks to their expertise for the provision of personalized services in a sensor-laden environment based on designing systems and algorithms that adapt to the user's preferences and needs.

This thematic issue presents some of the most recent advances in sensing and computing for smart healthcare. We wish to thank our colleagues Chen Chen (Fudan University, China), Caifeng Shan (Shandong University of Science and Technology, China), Ronald M. Aarts (Eindhoven University of Technology, The Netherlands) and Xi Long (Eindhoven University of Technology, The Netherlands) for their valuable work in producing this thematic issue as guest editors.

\section{Upcoming issues}

The following is a list of upcoming issues of JAISE:

- March 2022: Regular Issue.

- May 2022: Thematic Issue on Secure and Advanced Technology for Intelligent Environments.

- July 2022: Regular Issue.

- September 2022: Thematic Issue on Current Trends and the Future of Internet of Things in Industry and Enterprise.

- November 2022: Regular Issue.

- January 2023: Thematic Issue on Intelligent IoT for Autonomous Control and Ambient Intelligence.

More information on the call for papers to the future thematic issues is available on the webpage of JAISE at: https://www.iospress.com/catalog/journals/journal-of-ambient-intelligence-and-smart-environments 